\title{
Effectiveness of Guided Imagery on Stress and Coping among Wives of Alcoholics- A Quasi Experimental one Group Pre-Test Post-Test Research Design
}

\author{
Aarti $^{1}$, Srinivasan.P ${ }^{2}$, Manpreet Sharma ${ }^{3}$, Jyoti Sarin ${ }^{4}$ \\ ${ }^{I}$ Nursing Tutor, Department of Mental Health Nursing, M.M. Institute of Nursing, Maharishi Markandeshwar \\ (Deemed to be) University, Mullana, Haryana. India, ${ }^{2}$ Former Professor and HOD of Department of Mental \\ Health Nursing, M.M. College of Nursing, Maharishi Markandeshwar (Deemed to be) University, Mullana, \\ Haryana. India. Present: Nursing Tutor, AIIMS, Patna, ${ }^{3}$ Assistant Professor, ${ }^{4}$ PhD, Dean Faculty of Nursing, \\ Maharishi Markandeshwar (Deemed to be) University, Mullana, Haryana. India
}

\begin{abstract}
Alcoholism is one of the major health and social problem all over the world. It is the third leading psychiatric problem in the world today. Addiction is a family problem and is a major source of stress for family members.

Objectives: 1. To assess and compare the stress and coping before and after administration of Guided Imagery among wives of alcoholics. 2. To determine the relationship between stress and coping among wives of alcoholics. 3. To determine the association of stress and coping with the selected variables among wives of alcoholics.

Methodology: Quasi experimental study with one group pre-test post-test design. A total 33 wives of alcoholics were selected by using purposive sampling technique. Tools: selected variables, Modified Perceived Stress Scale and Brief COPE Scale were used. Guided Imagery intervention was given daily for six days and each session was of 30 minutes which includes 5 minutes deep breathing exercise before and after the active session of guiding with focused background music. Daily guided imagery sessions were divided on different themes. Post test was taken on $8^{\text {th }}$ day. Reliability of tool was estimated with Cronbach Alpha (internal consistency). The descriptive and inferential statistics were applied by using SPSS version 16.

Results: Kolmogorov Smirnov test was applied to check the normality of the data and data was normally distributed; hence parametric tests were applied. Findings of the study indicated that Guided Imagery was effective in reducing stress [" $\mathrm{t}$ " $(32)=20.05(\mathrm{p}=0.00)$ ] and improving the adaptive coping [" $\mathrm{t}$ " $(32)=$ $6.91(\mathrm{p}=0.00)]$ and reducing maladaptive coping $[" \mathrm{t} "=6.87(\mathrm{p}=0.01)]$ among wives of alcoholics. There was significant moderate negative correlation between stress and adaptive coping and there was significant association of stress, adaptive coping and maladaptive coping with selected variables such as number of children, age, monthly income and type of family. Further multiple regression was performed to check the predictability of selected independent variables on stress. Conclusion: Guided Imagery was effective in reducing stress and improving adaptive coping among wives of alcoholics.
\end{abstract}

Keywords: Alcoholism, Wives of alcoholics, Guided Imagery, De-addiction.

\section{Corresponding Author:}

Aarti

Nursing Tutor, M.M. Institute of Nursing, Maharishi Markandeshwar (Deemed To Be) University, Mullana- 133 207,( Ambala) Haryana, India E-mail: aartisainimani@gmail.com

\section{Introduction}

Alcoholism was identified as a contributing factor in the deaths of 30 percent of those who died from alcohol poisoning from 2010 to 2012. (CDC). About 100, 000 people die each year from alcohol-related causes: drinking and driving crashes, other accidents, falls, fires, 
alcohol-related homicides and suicides. (NCAAD). ${ }^{1}$

Addiction is a family problem and is a major source of stress for family members. Alcohol addiction causes family disruption as the addicted person ignores his responsibilities which further leads in disrupted family roles and impaired family communication. ${ }^{2}$

Stress is a common problem, so it is very important to learn how to identify stress and one must know about stress reduction techniques. Relaxation therapies help to reduce stress and in improving one's ability to cope with stress and stressful situations. ${ }^{2}$

\section{Methodology}

A quasi experimental one group pre-test post-test research design was used for this study. Wives aged between 18 to 60 years, present at the time of data collection, willing to participate in the study and able to understand and speak Hindi, English and Punjabi were included in the study. The wives of alcoholics who were having no stress (scored 0 in perceived stress scale), suffering with mental illness and whose husbands had poly substance abuse without alcohol or abused with substance other than alcohol were excluded from the study. Thirty three participants were enrolled in the study with purposive sampling technique. Data was collected by using selected variables, Modified Perceived stress scale and Brief COPE scale.

\section{Description of Data Collection Tool}

\section{Description of Selected Variables:}

It consisted of 18 items related to selected variables such as age, religion, educational status of self (wife of alcoholic) and husband, occupation self and husband, monthly income (in rupees), Socio-economic class, place of living, duration of marriage, number of children, type of family, duration of husband alcohol use, duration of husband's stay in de-addiction centre, previous history of husband's stay in de-addiction centre, any other substance used, associated health problem/chronic illness (self) and (husband). The items were prepared with the help of literature, expert's opinions and investigators personal experience.

\section{Modified Perceived Standardized Stress Scale:}

A standardized scale was modified which consisted of 10 items with 5 point rating scale out of which 6 items were negative which was scored in direct order and 4 positive items was scored in reverse direction. The questions asked about the feelings and thoughts during the last month and were modified as the questions were asked about the feelings and thoughts during the last week. Tool was incorporated in the study after getting prior permission from the tool developer and the modification was done to be used in Indian setting.

\section{Brief COPE Scale:}

A standardized tool was used to assess the coping among wives of alcoholics. It consists of 28 items with 4 point rating scale (16 items of adaptive coping and 12 items of maladaptive coping). Interpretations were based on mean percentage for both adaptive and maladaptive coping. Higher the mean percentage resembles use of adaptive or maladaptive coping style.

\section{Procedure}

After obtaining the formal administrative approval from Chief Medical Officer of Civil Hospital Ambala city, final study data was collected from $9^{\text {th }}$ September to $7^{\text {th }}$ December 2017. Thirty three wives of alcoholics were selected by using purposive sampling technique from selected De-addiction centre of Ambala City, Haryana. Written consent was taken. On day 1 pre assessment was done by administering the tool selected variable, modified perceived stress scale to assess the stress and brief COPE scale to assess the coping with self-report (interview) technique. Guided imagery intervention was given daily for 6 days from day-2 to day-7. Application of GI was divided in three phases and each session was of 30 minutes which includes 5 minutes deep breathing exercise as a warm up, 5 minutes deep breathing exercise at the end and 20 minutes of guiding. Guided imagery was actively given by the researcher by her own voice in live session rather than recorded sessions. Guided sessions were divided on basis of different themes and were based on the previous research evidences. Themes: Day-1 Natural guiding for individual. Day-2 Natural guiding with loved ones. Day-3 Spiritual guiding. Day-4 Deep relaxation guiding. Day-5 Meditation guiding (to get rid of negative thoughts). Day-6 Individual choice. Accordingly on day-8 post assessment was done.

\section{Data Analysis}

\section{Descriptive statistics}

-Frequency and Percentage distribution to describe 
selected variables. alcoholics.

- Range, Mean, Median, SD, and Mean Difference to describe in terms of stress and coping among wives of

\section{Inferential statistics}

- Paired' $t$ ' test to check the pre-test and post-test score differences.

- Pearson's correlation to check the correlation between stress and coping.

ANOVA and independent ' $t$ ' test to check the association

- Step wise Multiple Regression to check the predictability of multiple independent variables on stress.

\section{Results}

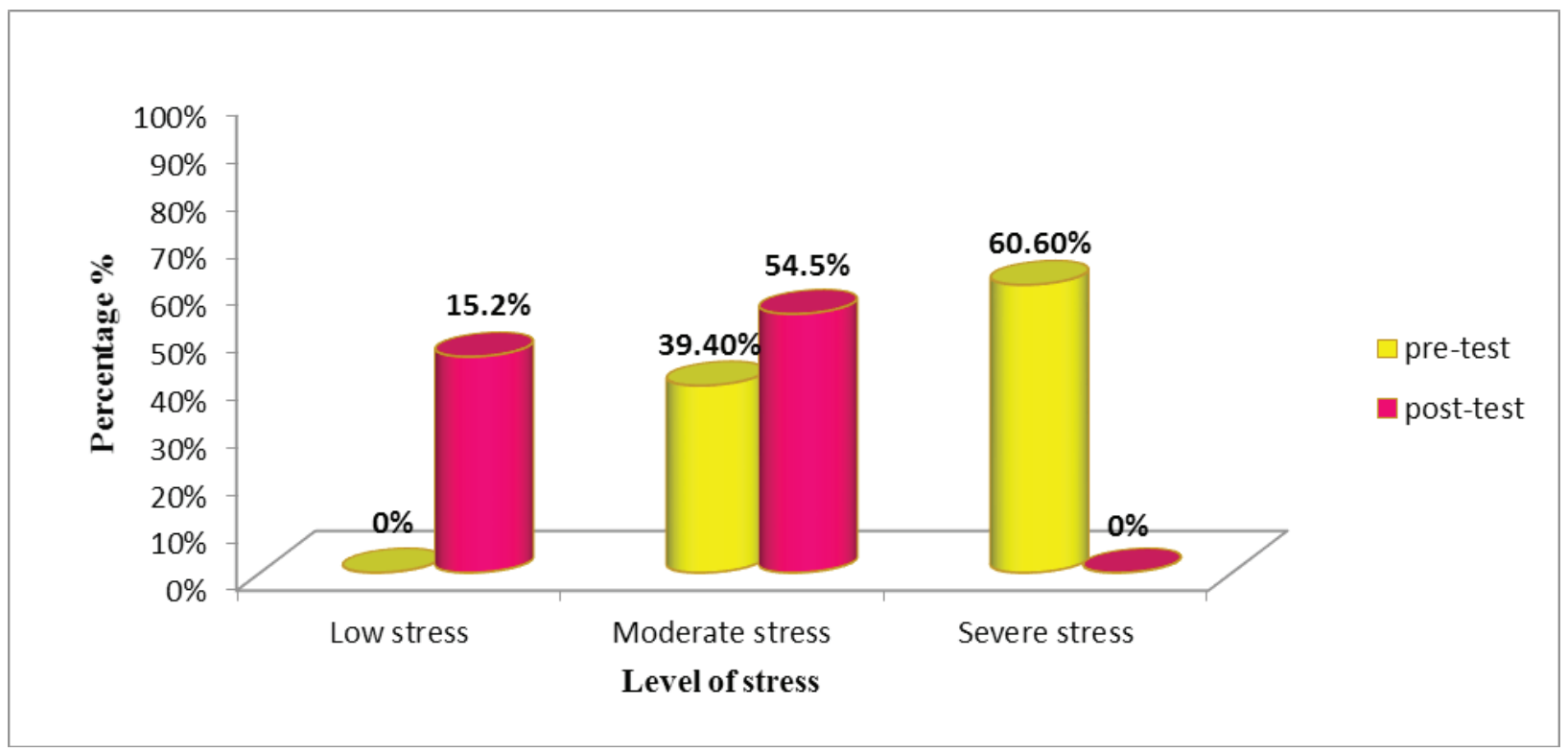

FIGURE 1- frequency and percentage distribution of wives of alcoholics in terms of level of stress.

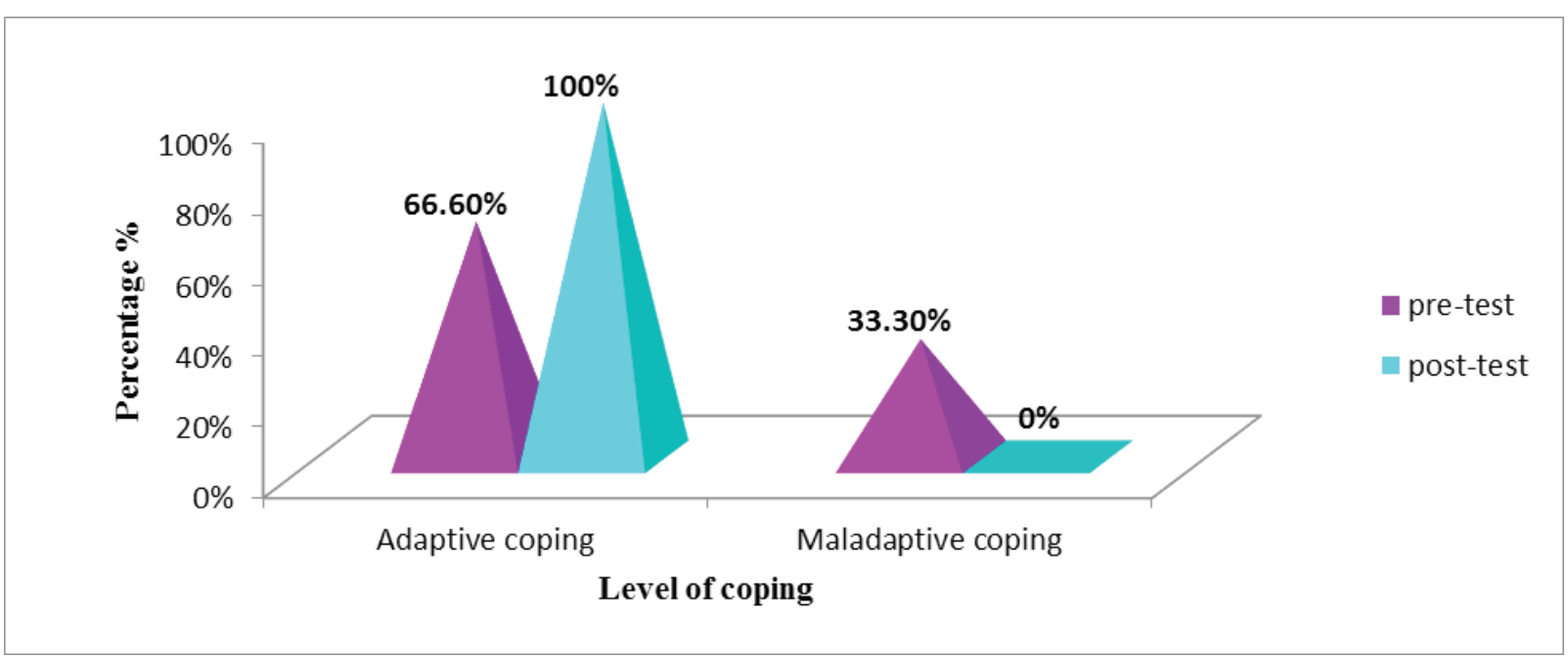

FIGURE 2- frequency and percentage distribution of wives of alcoholics in terms of level of adaptive and maladaptive coping. 
Table 1: Mean, MD, SD of difference, $\mathrm{SE}$ of mean difference and ' $t$ ' value of stress and coping. $N=33$

\begin{tabular}{|c|c|c|c|c|c|c|c|c|}
\hline Variable & Test & Mean \pm SD & MD & SDD & SEMD & 't' value & df & P value \\
\hline Stress & $\begin{array}{l}\text { Pre-test } \\
\text { Post-test }\end{array}$ & $\begin{array}{l}27.24 \pm 2.92 \\
14.91 \pm 4.82\end{array}$ & 12.33 & 3.53 & 0.615 & 20.05 & 32 & $0.00^{*}$ \\
\hline $\begin{array}{l}\text { Coping } \\
\text { Adaptive }\end{array}$ & $\begin{array}{l}\text { Pre-test } \\
\text { Post-test }\end{array}$ & $\begin{array}{l}27.52 \pm 5.51 \\
31.82 \pm 4.77\end{array}$ & 4.30 & 3.57 & 0.62 & 6.91 & 32 & $0.00 *$ \\
\hline Maladaptive & $\begin{array}{l}\text { Pre-test } \\
\text { Post-test }\end{array}$ & $\begin{array}{l}18.76 \pm 2.85 \\
14.21 \pm 3.10\end{array}$ & 4.54 & 3.80 & 0.66 & 6.87 & 32 & $0.00 *$ \\
\hline
\end{tabular}

*Significant $(\mathrm{p} \leq 0.05)$

$\mathrm{t}(32)=2.037$

Above table-1, shows effectiveness of the Guided Imagery in reducing stress, increasing the adaptive coping and decreasing the maladaptive coping among wives of alcoholics.

Table 2: Correlation between Stress and Coping among Wives of Alcoholics

$\mathrm{N}=33$

\begin{tabular}{|l|l|l|l|}
\hline Correlation & & Adaptive coping & Maladaptive coping \\
\hline & & & \\
Stress & Pre-test & $-0.396\left(0.02^{*}\right)$ & $-0.201(0.26) \mathrm{NS}$ \\
& Post-test & $-0.458\left(0.00^{* *}\right)$ & $-0.17(0.55) \mathrm{NS}$ \\
& & & \\
\hline
\end{tabular}

*- Mild/Weak negative Correlation ${ }^{*}$ Significant $(p=\leq 0.05)$

** - Moderate Negative Correlation ${ }^{* *}$ Significant $(\mathrm{p}=\leq 0.01)$

$r(31)=0.291^{\text {NS }}$ - Not Significant

There was positive association of stress among wives of alcoholics with number of children $(\mathrm{F}=6.244$, $\mathrm{p}=0.002$ ) \{Wives who were having no children had higher mean (20.67) stress score than others\}, adaptive coping with age $(\mathrm{F}=4.304, \mathrm{p}=0.013)$ and monthly income $(\mathrm{F}=3.964, \mathrm{p}=0.008)$ and maladaptive coping with type of family $(\mathrm{t}=1.502, \mathrm{p}=0.025)$ at 0.05 level of significance.
Step wise regression analysis showing predictability of multiple independent variables (age and skilled worker - occupation of husband) on stress in pre-test (multiple correlation coefficient) table 3 which revealed that the age alone at $1^{\text {st }}$ level of model had prediction with variability of $46.7 \%\left(\mathrm{R}^{2}=0.46\right)$. When age is 
combined with skilled worker - occupation of husband (reference group- unemployed) at $2^{\text {nd }}$ level of model, then both variables combined had prediction with variability of $58.8 \%\left(\mathrm{R}^{2}=0.58\right)$. Age alone had higher predictability in comparison to $2^{\text {nd }}$ model.

Table- 3: Step Wise Regression Showing the Predictability of Multiple Independent Variables on Stress (Multiple Correlation Coefficient) in Pre-Test N=33

\begin{tabular}{|l|l|l|l|l|l|}
\hline Model & R value & R square & F value & d.f. & P value \\
\hline Age & 0.68 & 0.46 & 27.16 & $1 / 31$ & $0.000^{*}$ \\
\hline $\begin{array}{l}\text { Age and } \\
\text { Skilled worker (occupation of husband) }\end{array}$ & 0.76 & 0.58 & 8.77 & $2 / 30$ & $0.006^{*}$ \\
\hline
\end{tabular}

*significant $(\mathrm{p} \leq 0.05)$

Step wise regression showing predictability of Number of Children and any other substance used with alcohol on stress in post-test (multiple correlation coefficient) table-4. The number of children alone at $1^{\text {st }}$ level of model had prediction with variability of $37.2 \%\left(\mathrm{R}^{2}=0.37\right)$. When number of children is combined with any other substance used with alcohol at $2^{\text {nd }}$ level of model, then both variables combined had prediction with variability of $45.8 \%\left(\mathrm{R}^{2}=0.45\right)$ which means number of children alone had higher predictability in comparison to $2^{\text {nd }}$ model.

Table-4: Step Wise Regression Showing the Predictability of Multiple Independent Variables on Stress (Multiple Correlation Coefficient) in Post-Test $\mathrm{N}=33$

\begin{tabular}{|l|l|l|l|l|l|}
\hline Model & R value & R square & F value & d.f. & P value \\
\hline Number of children & 0.61 & 0.37 & 18.37 & $1 / 31$ & $0.000^{*}$ \\
\hline $\begin{array}{l}\text { Number of children, any other } \\
\text { substance used with alcohol }\end{array}$ & 0.67 & 0.45 & 4.75 & $2 / 30$ & $0.03^{*}$ \\
\hline
\end{tabular}

*Significant $(\mathrm{p} \leq 0.05)$

Regression coefficient was performed to check the predictability of individual independent variables (age and skilled worker - occupation of husband) in pre-test table 5. As there was predictability of age and skilled worker - occupation of husband in multiple correlation coefficient, the direction of predictability for variables is as if the variable at the first level of model when only age is included in the statistics, if the age is increasing in years by 1 point the stress level is decreasing by 0.2 points $(-0.21)$. So when both the variables were combined at $2^{\text {nd }}$ level of model, when age increases by 1 point then the stress among wives of alcoholics decreases by 0.24 points which is more in $2^{\text {nd }}$ level of model as compared to $1^{\text {st }}$ level of model and skilled worker as husband occupation (with unemployment as reference group) the direction of prediction for the variables is as if the skilled worker - occupation of husband is increasing by 1 point, then the stress in wives was increasing by four points (4.348). 
Table-5: Step Wise Regression Analysis Showing the Significant Predictability of Selected Individual Independent Variables on Stress in Pre-Test (Regression Coefficient) N=33

\begin{tabular}{|c|c|c|c|c|c|}
\hline Model & $\begin{array}{l}\text { Unsta } \\
\text { Coeffi } \\
\text { B Std }\end{array}$ & & $\begin{array}{l}\text { Standarized } \\
\text { Coefficients } \\
\text { B }\end{array}$ & $\mathbf{t}$ & Sig. \\
\hline $\begin{array}{l}\text { 1.(Constant) } \\
\text { Age }\end{array}$ & $\begin{array}{l}34.77 \\
-0.21\end{array}$ & $\begin{array}{l}1.49 \\
0.04\end{array}$ & -0.68 & $\begin{array}{l}23.28 \\
-5.21\end{array}$ & $\begin{array}{l}0.000 * \\
0.000^{*}\end{array}$ \\
\hline $\begin{array}{l}\text { 2.(Constant) } \\
\text { Age } \\
\text { Skilled Worker } \\
\text { (Occupation of Husband }\end{array}$ & $\begin{array}{l}35.55 \\
-0.24 \\
4.34\end{array}$ & $\begin{array}{l}1.36 \\
0.03 \\
1.46\end{array}$ & $\begin{array}{l}-0.77 \\
0.36\end{array}$ & $\begin{array}{l}26.12 \\
-6.40 \\
2.96\end{array}$ & $\begin{array}{l}0.000^{*} \\
0.000^{*} \\
0.000 *\end{array}$ \\
\hline
\end{tabular}

*significant $(\mathrm{p} \leq 0.05)$

Regression coefficient was performed to check the predictability of individual independent variable (number of children, any other substance used with alcohol) in post-test table-6. The direction of predictability for variables is

as: if at the $1^{\text {st }}$ level of model when only No. of children is included in the statistics: if the number of children is increasing by 1 point the stress level is decreasing by 2.4 points $(-2.429)$. So when both the variables were combined at $2^{\text {nd }}$ level of model, then number of children had less predictability as compared to $1^{\text {st }}$ level of model. Any other substance used with alcohol, the direction of prediction is as: if the chance of consuming any other substance with alcohol is increasing by 1 point, then the stress in wives was decreasing by 3.5 points $(-3.529)$ which further infers that if the husband uses any other substance with alcohol then the stress is decreasing among wives.

Table-6: Step Wise Regression Analysis Showing the Predictability of Selected Independent Variables on Stress in Post-Test (Regression Coefficient) $\mathrm{N}=33$

\begin{tabular}{|c|c|c|c|c|c|}
\hline Model & $\begin{array}{l}\text { Unsta } \\
\text { Coeffi } \\
\text { B Std }\end{array}$ & & $\begin{array}{l}\text { Standarized } \\
\text { Coefficients } \\
\text { B }\end{array}$ & $t$ & Sig. \\
\hline $\begin{array}{l}\text { 1.(Constant) } \\
\text { Number of Children }\end{array}$ & $\begin{array}{l}19.69 \\
-2.42\end{array}$ & $\begin{array}{l}1.30 \\
0.56\end{array}$ & -0.61 & $\begin{array}{l}23.28 \\
-5.21\end{array}$ & $\begin{array}{l}0.000^{*} \\
0.000^{*}\end{array}$ \\
\hline $\begin{array}{l}\text { 2.(Constant) } \\
\text { Number of Children } \\
\text { Any other Substance used with Alcohol }\end{array}$ & $\begin{array}{l}19.81 \\
-2.11 \\
-3.52\end{array}$ & $\begin{array}{l}1.23 \\
0.55 \\
1.61\end{array}$ & $\begin{array}{l}-0.53 \\
0.30\end{array}$ & $\begin{array}{l}16.06 \\
-3.81 \\
-2.18\end{array}$ & $\begin{array}{l}0.000^{*} \\
0.000^{*} \\
0.003^{*}\end{array}$ \\
\hline
\end{tabular}

*significant $(\mathrm{p} \leq 0.05)$ 


\section{Discussion}

In the present study, $60.6 \%$ wives of alcoholics were having severe stress, $66.6 \%$ were having adaptive coping and $33.3 \%$ were having maladaptive coping. These all findings was consistent with the findings of the study conducted by Nagesh V (2015) ${ }^{3}$ where it was found that highest percentage $100 \%$ of the wives of alcoholics had Moderate stress, Further assessment of the overall levels of coping shows that highest percentage $98.33 \%$ of the wives of alcoholics were able to cope to some extent, $1 \%$ of wives were able to cope effectively.

In the present study, Guided Imagery was found to be an effective intervention in reducing stress among wives of alcoholics as there was significant reduction in stress score (' $\mathrm{t}$ ' $=20.056, \mathrm{p}=0.00$ ). This finding was consistent with the findings of the study conducted by Dell, Samuel's (2011) ${ }^{4}$ where the results revealed that majority of the spouse of alcoholics $[\mathrm{F}(21,11)=1.05, \mathrm{p}>.05]$ benefitted with the guided imagery technique to handle their life stress. Another study also well support the findings of present study conducted by James and Goldman's $(2001)^{5}$ where they found that Guided Imagery was effective in reducing stress among spouses of alcoholics. Further these findings are consistent with the study conducted by Divyabala S and Srinivasan P $(2013)^{6}$ which revealed that after intervention, there was a significant difference in the mean score of stress before and after guided imagery i.e the calculated ' $t$ ' value was 19.613 and it was statistically significant at 0.05 level.

In the present study, Guided Imagery was found to be an effective intervention in terms of coping (adaptive coping ' $\mathrm{t}$ ' $=6.91, \mathrm{p}=0.00$ and maladaptive coping ' $\mathrm{t}$ ' $=6.87$, $\mathrm{p}=0.00$ ). This finding was consistent with the findings of the study conducted by vanitha rani, J Venkatesan and R Vijayaragavan $(2016){ }^{6}$ where the results of the study revealed that, the calculated ' $\mathrm{t}$ ' test value for stress $(' t '=22.96)$ and coping $(' t '=26.60)$ had a significant difference between the pre and post test levels of stress and coping among the caregivers of alcohol dependents at 0.05 level of significance.

In the present study, there was moderate negative correlation of stress with adaptive coping $[\mathrm{r}=-0.458$, $\mathrm{p}=0.00]$. The findings of the present study was partially supported by James and Goldman's $(2001)^{5}$ quasi experimental study where the study results $(\mathrm{r}(148)=.17$, $\mathrm{p}=.07)$ revealed that there is a significant relationship between Guided imagery and intellectual life skill training and the stress reduction among the spouse of alcoholics. Another study also well supported the findings of present study conducted by vanitha rani, J Venkatesan and R Vijayaragavan $(2016){ }^{8}$ where the results revealed that there was moderate negative correlation between the post test scores of stress and coping i.e. $r=-0.7$ for both groups.

In the present there was significant association of number of children $(\mathrm{p}=0.002)$ with stress and type of family $(\mathrm{p}=0.025)$ with maladaptive coping. These findings of the study are consistent with the study conducted by Nagesh V $(2015)^{3}$ where they found that only age and number of children had significant association with perceived stress $\left(\chi_{(3)=}^{2} 8.67\right.$ and $\chi_{(3)=}^{2}$ $7.55)$ at 0.05 level of significance and in the coping type of family $\left(\chi_{(1)}^{2}=5.455\right)$ had association.

\section{Conclusion}

Guided Imagery was effective in reducing stress and improving adaptive coping among wives of alcoholics.

\section{Conflict of Interest: NIL}

\section{Funding Sources: SELF}

Ethical approval: The ethical clearance was obtained from university research ethics committee of Maharishi Markandeshwar University Mullana, Ambala (MMU/IEC/197) and the study was carried out in accordance with the guidelines laid by Indian Council of Medical Research ICMR(2006). The permission was taken to conduct the study in the De-addiction centre (from Chief Medical Officer of Civil Hospital Ambala city).

\section{References}

1. Alcoholism Statistics 2015 [Internet]. Cited 2018 Feb. 2]. Available from: http://www. medicaldictionary.thefreedictionary.com

2. Statistics obtained from: [internet]. [Cited 2018 Feb.5] Available from: http://www.who.int/ substance_abuse/facts/alcohol/en/

3. Nagesh V. Stress and Coping among the Wives of Alcoholics admitted in Selected De-Addiction Centers. Asian Journal of Nursing Education and Research. 2015;5 (3):373.

4. Dell, Samuel's. Study to assess the level of stress and to evaluate the effectiveness of guided imagery among spouses of alcoholics. 
374 Medico-legal Update, July-September 2020, Vol.20, No. 3

5. James and Goldman James,J.E, Goldman, M.Behavior trends of wives of

6. Divyabala $\mathrm{S}$ and Srinivasan $\mathrm{P}$. Effectiveness of guided imagery on stress among spouse of alcoholics. International Journal of Applied Research 2016; 2(8): 565-567 Mrs.Vanitha Innocent
Rani, Dr.J.Venkatesan and Dr,R.Vijayaragavan. Effectiveness Of Coping Strategies On Stress And Coping Among The Caregivers Of Alcohol Dependents At Selected De-Addiction Centres, Thanjavur. Int J Pharm Bio Sci 2016 July ; 7(3): (B) 1092 - 1095 ISSN 0975-6299 